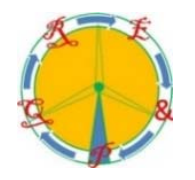

\title{
Numerical study of the cooling capacity of several alternative liquids in zig-zag cooling system of a power transformer
}

\author{
Agustín Santisteban $^{1}$, Fernando Delgado ${ }^{1}$, Alfredo Ortiz ${ }^{1}$, Inmaculada Fernandez ${ }^{1}$, Carlos J. Renedo ${ }^{1}$ \\ ${ }^{1}$ Department of Electrical and Energy Engineering \\ E.T.S.I. Industriales y de Telecomunicación, Cantabria University \\ Av. De Los Castros, s/n, 39005, Santander (Spain) \\ Phone/Fax number:+34 9422013 76/85; e-mail: delgadof@unican.es
}

\begin{abstract}
Mineral oil is the usual coolant of the power Transformers. Nonetheless, the high risk of fire of this liquid due to its low ignition point and its scarce biodegradability has promoted the development of dielectrics alternative fluids with better physical-chemical properties. However, these new liquids have to be as good coolants as mineral oil in order to maintain the power transformer performance. This numerical study analyzes the coolant capacity of some of these new commercial liquids (a natural ester, a synthetic ester, and a silicone oil) by using the zig-zag cooling system of the low voltage winding of a real power transformer. Two types of thermal-fluid studies (parametric and time-dependent studies) have been made by using a 3D model of this system. The comparison of temperatures obtained from the parametric study (different inlet flow rates) allow us to say that the worst coolant is the silicone oil. Also, it can be say that a significant increase in the inlet flow rate produces mild drops of hot-spots temperatures and no modification in the initial temperature distribution. For the timedependent study ( $25 \%$ of overload during 1 hour), the hot-spot temperature exceed the limits, which negatively affects the aging speed of the insulating paper and therefore the transformer lifetime.
\end{abstract}

\section{Key words}

Power transformer, zig-zag cooling system, alternative dielectric liquids, coolant capacity, FEM simulation

\section{Introduction}

Transformers are one of the main elements in transmission and distribution networks of power supply since they allow long distance of power transmission minimizing losses. Due to the requirements of their performance, there are cooling needs to be satisfied for an optimal operation. Mineral oil has been used during more than 100 years as a dielectric cooling liquid, and it is still in use due to its great price-performance ratio. However, the use of this liquid in some applications (ships, public buildings...) carries serious risks due to its low flash and ignition points. Furthermore it presents environmental troubles because of being a petroleum derivate. Furthermore, it presents environmental troubles because of being a petroleum derivative.

These adverse properties have encouraged to start a research line in which a development of alternative dielectric liquids (based on natural esters, synthetic esters and silicon oils) that solve the previous mentioned problems is intended. These liquids also must have good cooling properties to assure a good performance of the transformer.

For that reason, it becomes necessary to determinate the cooling capacity of the new dielectric liquids. It can be determined by using experimental techniques (monitoring of transformers refrigerated with these liquids) or theoretical methods. Among these last ones, two different methodologies can be adopted. First one is based on concentrated parameters and the second one consist in a numerical analysis. The method used in this paper is the second one by means of the Finite Element Method (FEM).

Several papers have been published in last decade using FEM. Nonetheless, we have to mention that the main goal of practically all these papers is the determination of the velocity and temperature profiles of a mineral oil inside a 2D section of one winding [1], [2], [3].Among these papers, work made by Torriano et al. in 2010 can be pointed out. A 2D-model of a pass of a Low Voltage Winding (LVW) that belongs to a 3phase disc-type transformer was simulated, thus obtaining the effect of the model accuracy, the mass flow rate and inlet boundary conditions on the flow and temperature profiles. They also determined the location of the hot-spots in the winding [4]. More recently, in 2012, the same authors carried out a comparison between 2D and 3D models of the same geometry, thus determining the existence of threedimensional fluid flow phenomena that cannot be obviated such as it occurs in the 2D-model [5]. Again, in the same year, a 3-D model of a 15-kVA ONAN transformer was carried out by Rosillo et al. in which oil velocity profile and oil and winding temperature distribution were calculated and experimentally validated in accordance with the IEEE-1995 Loading Guide [6]. Recently, in 2015, Lecuna et. Al. carried out the comparison of the thermal-fluid behavior of some alternative liquids with that of a mineral oil by means of several parameters ( $\mathrm{T}, \mathrm{v}, \mathrm{Q}, \mathrm{h}$ and $\mathrm{P}$ (cooling criterion)). These parameter were calculated by using the numerical results of the simulation of a 3D-model of a LVW that belongs to a power transformer with ONAN refrigeration, [7].

$2 \mathrm{D}$ analysis is discarded in this paper due to there is heat transfer in all directions of the volume of our model; also, this $2 \mathrm{D}$ analysis does not allow determinate the exact location of the hot-spots. 
For that reason, a 3D-section of the cooling ducts of the LVW of a real power transformer is used in this paper. Even more, this geometry is simulated using a physical model in which buoyancy and viscous forces are the only considered establishing the natural convection. As a result of this simulation, a comparison of temperature and velocity profiles of three alternative liquids (a silicone oil, a natural ester and a synthetic ester) is obtained. In order to carry out this work, a thermal-fluid analysis has been performed using different flow rates and a time-dependent study applying an overload of $25 \%$ during 1 hour. All of this work has been made using the Finite element-based software COMSOL Multiphysics 5.0 .

Section two presents a brief description of the 3D model that is used. Simulation results and their comparison are shown in the third section. Finally, conclusions are presented in the last section.

\section{Model definition}

In this section the model used in simulation will be described.

\section{A. Model Geometry}

The geometry studied consists in a LVW of a disc-type transformer with zig-zag cooling. This winding consists in 78 copper discs divided in 4 passes where only the first two will be considered. The winding is divided in 18 portions of $20^{\circ}$, each one symmetrical so it will be considered just a $10^{\circ}$ portion applying symmetry conditions (See Figure 1.b). A more detailed geometrical description of the transformer can be seen in [5].

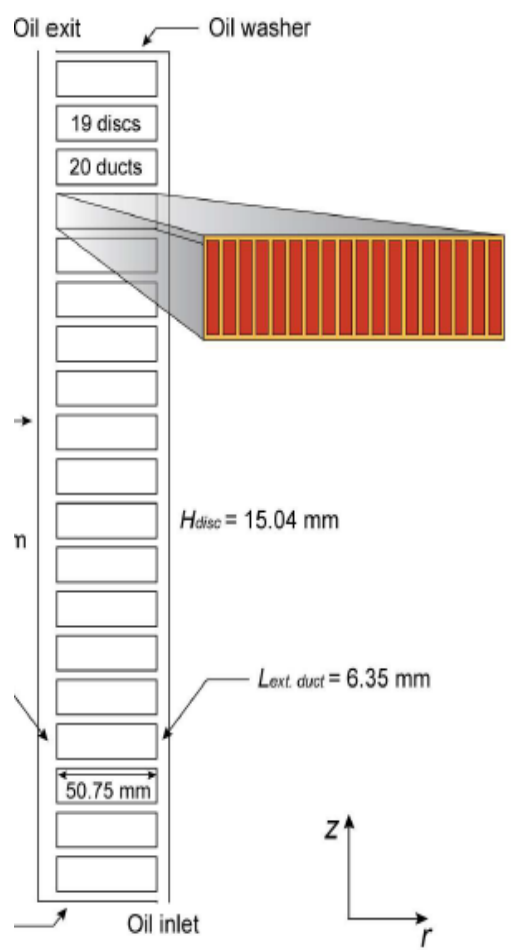

Fig. 1.a. Cross-section of a pass

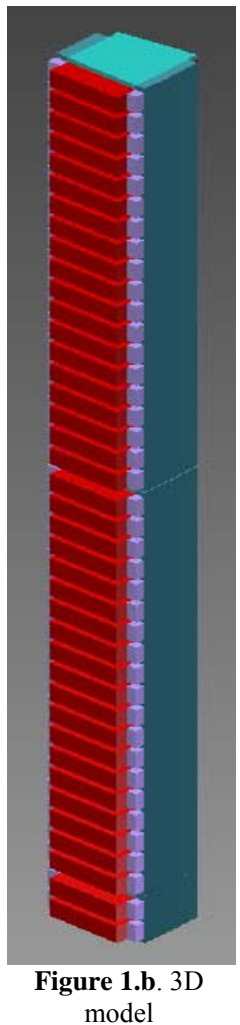

model
Figure 1. Geometrical model of the LVW winding studied
Each pass is formed by 19 discs, 20 horizontal ducts and 2 vertical ducts (See Figure 1.a). Fluid enters the pass through one vertical duct and leaves through the other, crossing the horizontal ducts. The inlet duct alternates between the inner duct and the outer duct in successive passes, so does the outlet duct.

\section{B. Physics considered}

Two different physics (heat transfer and fluid dynamics) are combined with the intention to apply them over the copper discs and fluid domains.

In relation to heat transfer, it is supposed a general energy balance defined by the differential eq. (1).

Where:

$$
\nabla(-k * \Delta T)=Q-\rho C_{p} u * \Delta T
$$

$k$ - Temperature-dependent thermal conductivity

$C_{p}$ - Temperature-dependent specific heat capacity

$\rho$ - Temperature-dependent density

$Q$ - Heating power per unit volume

$\boldsymbol{u}-$ Fluid velocity

Regarding the fluid dynamics, the mass and momentum conservations are considered by means of the NavierStokes equations, eqs. (2) and (3).

$$
\rho u * \nabla u=\nabla\left[\begin{array}{c}
-p I+\eta *\left(\nabla u+(\nabla u)^{T}\right) \\
-\left(\frac{2 \eta}{3}\right)(\nabla u) I \\
\nabla(\rho u)=0
\end{array}\right]+\rho g
$$

Where:

$$
\begin{aligned}
& p-\text { Pressure field } \\
& \eta \text { - Temperature-dependent viscosity } \\
& \text { I- Identity matrix } \\
& \boldsymbol{g} \text { - Gravity vector }
\end{aligned}
$$

The boundary conditions applied in the study are the following:

- Inlet and initial temperatures of the fluid: $46,7^{\circ} \mathrm{C}$

- Only exists convective heat flow in the exit ducts.

- There is axial symmetry.

- There are plane symmetry of velocities and temperatures

- Clamping elements (sticks, intersticks, cardboard cylinders, spacers) are considered adiabatic.

- Constant heat generation of $1.88 \mathrm{~W}$ (per degree and disc) reaching a total of $752 \mathrm{~W}$.

\section{Liquids studied}

Fluid properties considered in the physical model are density, heat capacity, thermal conductivity and kinematic viscosity. Table I shows the variation of these properties with the temperature. 
Table I. - Fluid-thermal properties of the alternative liquids studied

\begin{tabular}{|c|c|c|c|}
\hline & Natural ester & Synthetic ester & Silicone oil \\
\hline Density $\left[\mathrm{kg} / \mathrm{m}^{3}\right]$ & $\rho=1113.5-0.6587 \cdot T$ & $\rho=1185-0.7333 \cdot T$ & $\rho=1217-0.89 \cdot \mathrm{T}$ \\
\hline Heat capacity $[\mathrm{J} /(\mathrm{kg} \mathrm{K})]$ & $\mathrm{c}_{\mathrm{p}}=3134.7-10.171 \cdot \mathrm{T}+0.0209 \cdot \mathrm{T}^{2}$ & $c_{p}=1242.4+2.1983 \cdot T$ & $\mathrm{c}_{\mathrm{p}}=1800$ \\
\hline Thermal conductivity $[\mathrm{W} /(\mathrm{m} \mathrm{K})]$ & $\mathrm{k}=0.1717-6 \cdot 10^{-6} \cdot \mathrm{T}$ & $\mathrm{k}=0.1451-3 \cdot 10^{-3} \cdot \mathrm{T}-1 \cdot 10^{-8} \cdot \mathrm{T}^{2}$ & $\mathrm{k}=0.125$ \\
\hline Kinematic viscosity $\left[\mathrm{m}^{2} / \mathrm{s}\right]$ & $v=0.0827 \cdot \mathrm{e}^{-0.025 \cdot \mathrm{T}}$ & $v=0.3438 \cdot \mathrm{e}^{-0.03 \cdot \mathrm{T}}$ & $v=0.0013 \cdot \mathrm{e}^{-0.014 \cdot \mathrm{T}}$ \\
\hline
\end{tabular}

\section{Studies performed}

As it was mentioned in the introduction, two types of study are performed in this paper. First, a parametric study is executed. In this study, transformer cooling is analyzed at its nominal power with three values of the coolant inlet flow rate. The first value is the nominal flow rate mentioned in [5]. The other two values are this nominal flow rate increased in a $5 \%$ and $10 \%$, respectively. The aim of this study is determined the influence of the coolant flow rate on the hot-spot temperature and its location.

The second study consists in a time-dependent analysis in which the transformer suffers an overload of a $25 \%$ during 1 hour. The aim of this study is determine the length of the transient regime and the increase of the hot-spot temperature once reached the steady state.

\section{Results}
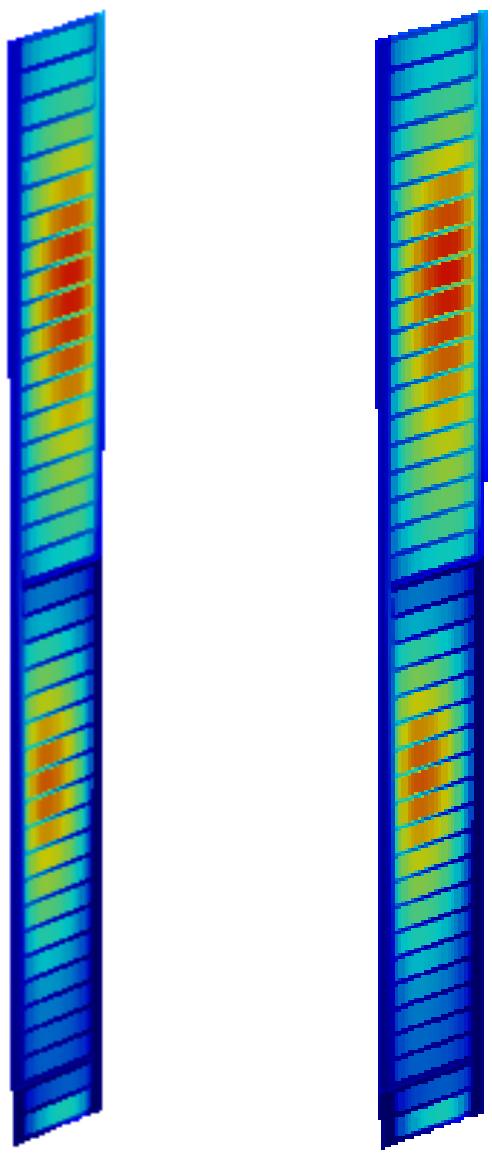

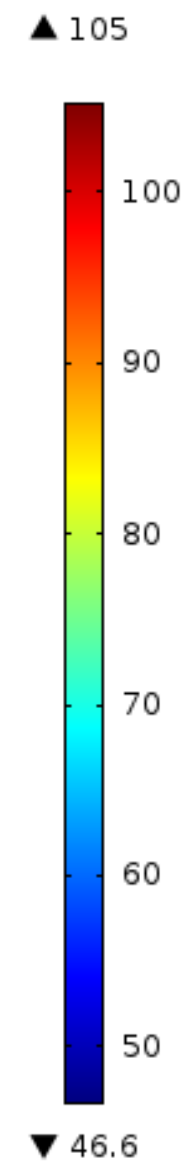

In this section, results obtained from simulations are shown.

\section{A. Parametric study}

Figure 2 shows temperatures obtained with all studied liquids with nominal inlet flow rate. It can be appreciated that the hottest areas are approximately located at $3 / 4$ of the total height. There is also perceived that cooling with silicon oil produces higher temperatures than both esters.

For all cases, the hot-spot location remains the same and is value is reduced between $2-3^{\circ} \mathrm{C}$ when the inlet rate increases in a $10 \%$

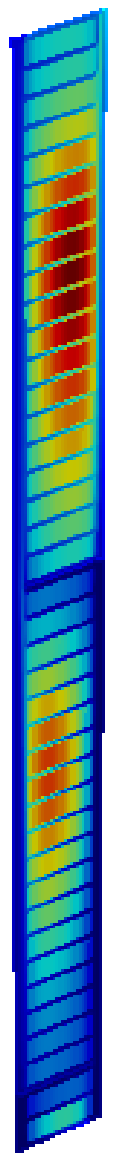

Figura 2.a. Natural ester Figura 2.b. Synthetic ester

Figura 2.c. Silicon oil

Figure 2. Temperature distributions with nominal inlet flow rate

Figure 3 presents the average temperature of copper discs for all liquids in each case of inlet flow rate. It is shown that for each liquid, temperature drops a $2-3 \%$ when inlet flow rate increases by $10 \%$.
It can be appreciated that the cooling capacity of both natural ester and synthetic ester is very similar since their value for the average disc temperature is almost the same 


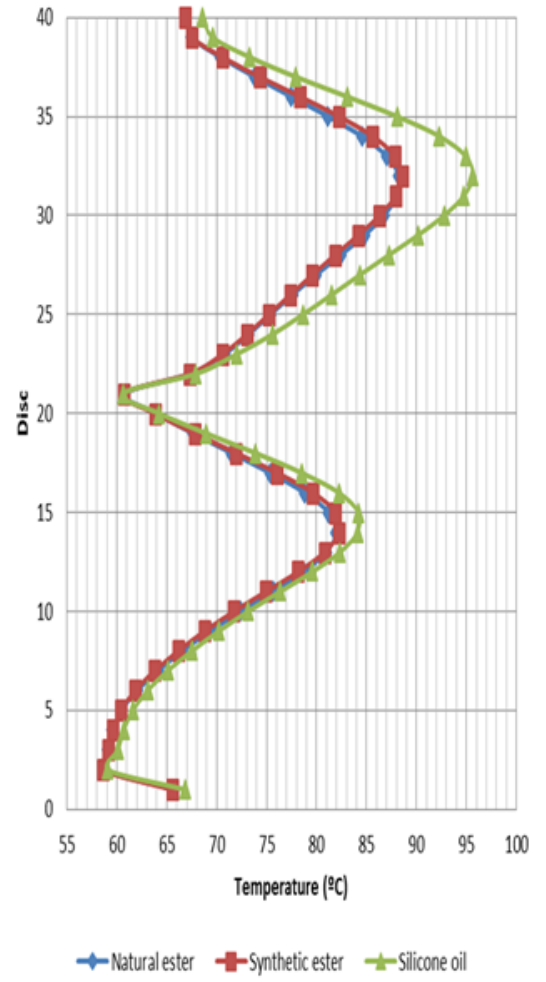

Figure 3.a. Nominal flow rate

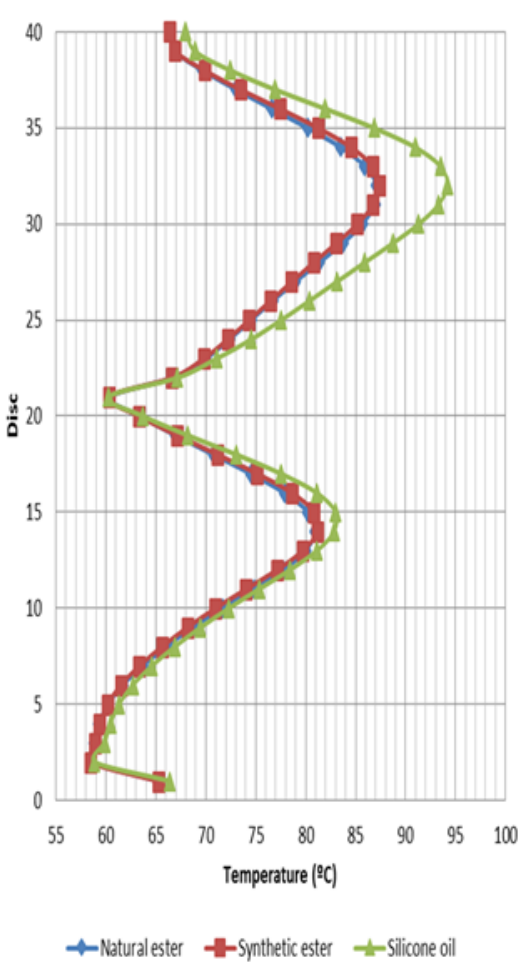

Figure 3.b. 5\% increased flow rate

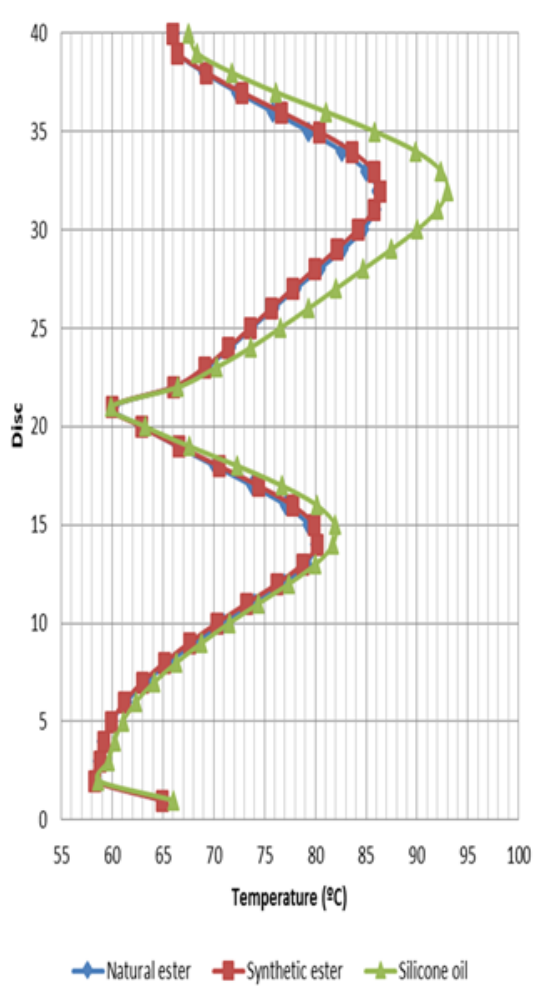

Figure 3.c. $10 \%$ increased flow rate

Figure 3. Average temperatures in discs with different inlet flow rates

It can be appreciated that the average velocities in the horizontal ducts, shown in Figure 4, are similar in each case of the study for all liquids.
It is also observed that velocity is higher in the first and last ducts of each pass in comparison to the intermediate ones, which means that those regions have better cooling.

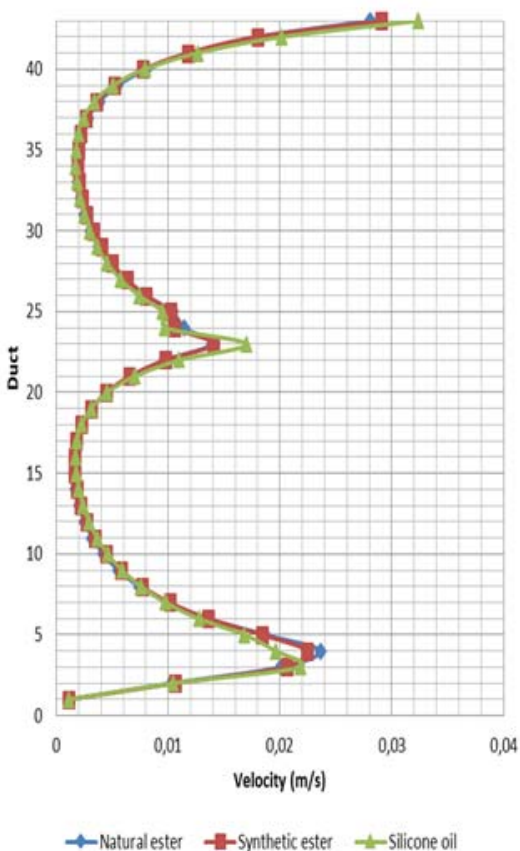

Figure 4.a. Nominal flow rate

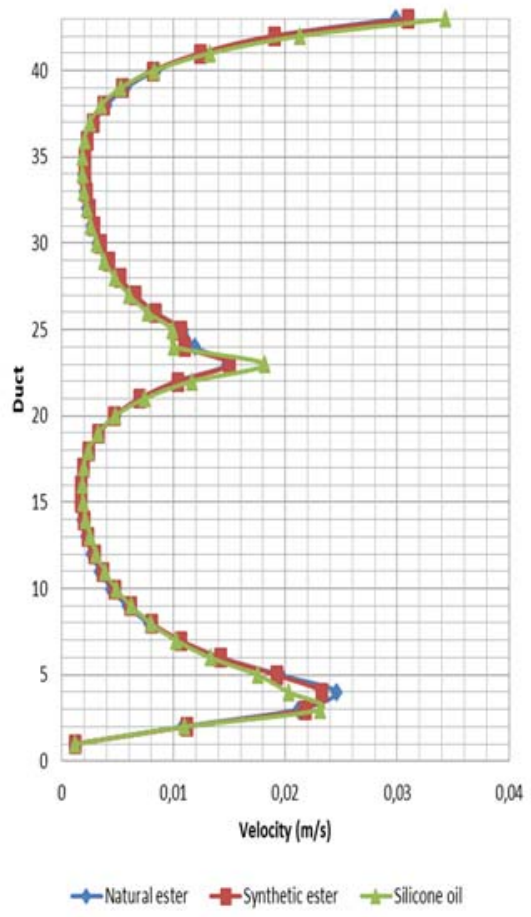

Figure 4.b. 5\% increased flow rate

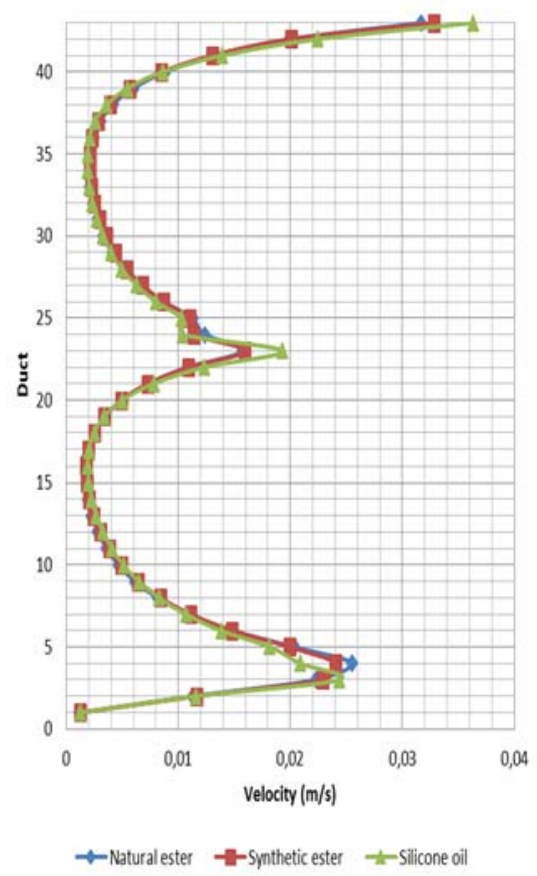

Figure 4.c. 10\% increased flow rate

Figure 4. Average temperatures in horizontal ducts

Table II presents some relevant data obtained from simulations, such as hot-spot temperatures $\left(\mathrm{T}_{\mathrm{HS}}\right)$, average fluid temperatures ( $\left.\mathrm{T}_{\text {avg,fluid }}\right)$, and average temperatures
$\left(\mathrm{T}_{\text {avg,outlet }}\right)$ and average velocities $\left(\mathrm{V}_{\text {avg,outlet }}\right)$ in the outlet. It can be appreciated that the outlet velocity have a close value for all liquids in each case of this study. 
Table II. Some temperatures and velocities obtained from the parametric study

\begin{tabular}{|r|c|c|c|c|c|c|c|c|c|}
\cline { 2 - 10 } \multicolumn{1}{c|}{} & \multicolumn{3}{c|}{ Natural ester } & \multicolumn{3}{c|}{ Synthetic ester } & \multicolumn{3}{c|}{ Silicone oil } \\
\cline { 2 - 11 } \multicolumn{1}{c|}{} & $100 \%$ & $105 \%$ & $110 \%$ & $100 \%$ & $105 \%$ & $110 \%$ & $100 \%$ & $105 \%$ & $110 \%$ \\
\hline$T_{\text {HS }}$ & 96.4 & 95.1 & 94 & 96.9 & 95.5 & 94.3 & 105.3 & 103.6 & 102.3 \\
\hline$T_{\text {avg,fluid }}$ & 57.1 & 56.7 & 56.3 & 57 & 56.5 & 56.1 & 58.5 & 58 & 57.5 \\
\hline$T_{\text {avg,outlet }}$ & 63.4 & 62.7 & 62.1 & 63.4 & 62.7 & 62 & 65.7 & 64.8 & 64.1 \\
\hline$V_{\text {avg,outlet }}$ & 93.4 & 98 & 102.6 & 93.2 & 97.8 & 102.4 & 93.6 & 98.2 & 102.7 \\
\hline
\end{tabular}

\section{B. Time-dependent study}

For the three liquids, the temporal evolution of the average temperatures of some discs are shown in Figure 5. It can be appreciated that for each liquid, steady state is reached between 18 and 24 minutes of overload application.

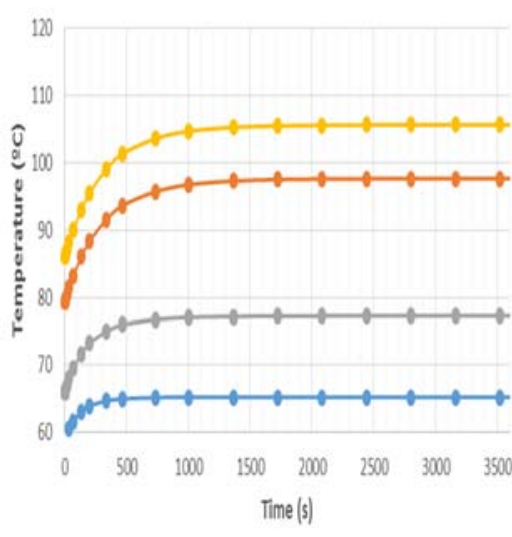

$\rightarrow$ Disco $\rightarrow$ Disco $15 \rightarrow$ Disco $22 \rightarrow-$ Disco 32

Figura 5.a. Natural ester

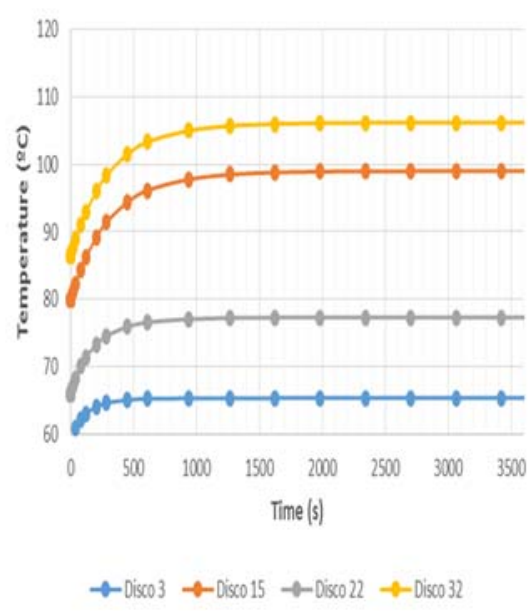

Figura 5.b. synthetic ester

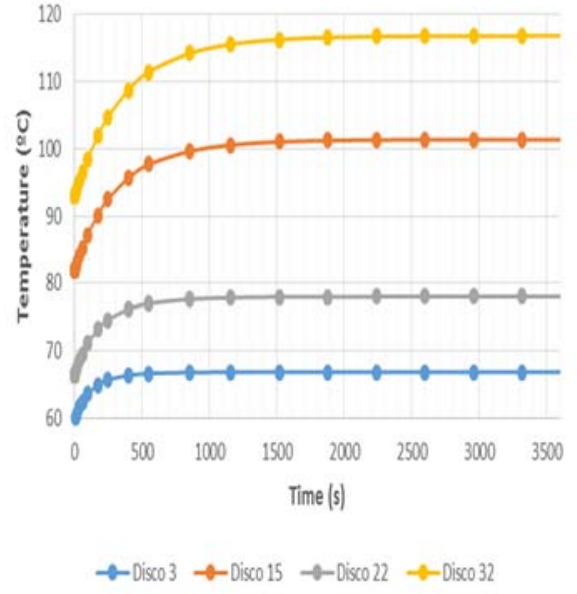

Figura 5.c. Silicone oil

Figura 5. Temporal evolution of the average temperatures of some dics

Table III presents some relevant data obtained from the time-dependent simulations, such as hot-spot temperatures ( $\left.\mathrm{T}_{\mathrm{HS}}\right)$, average fluid temperatures $\left(\mathrm{T}_{\text {avg,fluid }}\right)$, and average temperatures $\left(\mathrm{T}_{\text {avg,outlet }}\right)$ and average velocities $\left(\mathrm{v}_{\text {avg,outlet }}\right)$ in the outlet.

Table III. Some temperatures and velocities obtained from the time-dependent study

\begin{tabular}{|r|c|c|c|}
\cline { 2 - 4 } \multicolumn{1}{c|}{} & Natural ester & Synthetic ester & Silicone oil \\
\hline $\mathrm{T}_{\mathrm{HS}}$ & 117.3 & 118 & 130.7 \\
\hline $\mathrm{T}_{\text {avg,fluid }}$ & 61.2 & 61.1 & 63.4 \\
\hline $\mathrm{T}_{\text {avg,outlet }}$ & 70.4 & 70.4 & 73.8 \\
\hline $\mathrm{V}_{\text {avg,outlet }}$ & 103.1 & 102.6 & 103.3 \\
\hline
\end{tabular}

\section{Conclusion}

From the previously displayed results, some conclusions can be deduced.

First of all, hot-spot temperature is higher when using the silicon oil than when using both esters studied at its nominal flow rate. In the parametric study it is appreciated that a significant increase of the inlet flow rate produces mild drops of hot-spot temperature. Furthermore, hot-spot location is not modified.

For the time-dependent study it is worthy to distinguish that the steady-state is reached in the simulation time previously established. For this case, hot-spot temperature markedly increases though temperature profile is not significantly altered. New temperatures obtained are above limits established by international standards, which negatively affects the aging speed of the insulating paper and therefore the transformer lifetime.

\section{Acknowledgement}

The authors of this research wish to acknowledge to the Spanish Ministry of Science for the financial support to the National Research Project: Performance of the insulating systems in transformers: alternative dielectrics, thermalfluid modelling and post-mortem analysis (DPI201343897-P). 


\section{References}

[1] J. -. Mufuta, E. Van Den Bulck, "Modelling of the mixed convection in the windings of a disc-type power transformer," Appl. Therm. Eng., vol. 20, pp. 417-437, 2000

[2] N. El Wakil, N. -. Chereches, J. Padet, "Numerical study of heat transfer and fluid flow in a power transformer," Int. J. Therm. Sci., vol. 45, pp. 615626, 2006.

[3] E. Rahimpour, M. Barati and M. Schäfer, "An investigation of parameters affecting the temperature rise in windings with zigzag cooling flow path," Appl. Therm. Eng., vol. 27, pp. 1923-1930, 2007.

[4] F. Torriano, M. Chaaban, P. Picher, "Numerical study of parameters affecting the temperature distribution in a disc-type transformer winding," Appl. Therm. Eng., vol. 30, pp. 2034-2044, 2010.

[5] F. Torriano, P. Picher, M. Chaaban, "Numerical investigation of 3D flow and thermal effects in a disc-type transformer winding," Appl. Therm. Eng., vol. 40, pp. 121-131, 2012.

[6] M. E. Rosillo, C. A. Herrera and G. Jaramillo, "Advanced thermal modeling and experimental performance of oil distribution transformers," IEEE Trans Power Delivery, vol. 27, pp. 1710-1717, 2012.

[7] R. Lecuna, F. Delgado, P. Castro, A. Ortiz, I. Fernández and C. J. Renedo, "Thermal-fluid Characterization of Alternative Liquids of Power Transformers: a Numerical Approach," IEEE Transactions on Dielectrics and Electrical Insulation, 10/2015. 2015. 